\title{
Correlations between plasma homocysteine and MTHFR gene polymorphism and white matter lesions
}

\author{
Min $\mathrm{Li}^{1,2 \#}$, Bing $\mathrm{Fu}^{1,2 \#}$, Wanli Dong ${ }^{1}$ \\ ${ }^{1}$ Department of Neurology, the First Affiliated Hospital of Soochow University, Suzhou 215006, China, ${ }^{2}$ Department of Neurology, \\ the Second Hospital of Lianyungang, Lianyungang 222023, China \\ \#These authors contributed equally to this work.
}

\begin{abstract}
This study aims to investigate the correlation between the plasma homocysteine (Hcy) level and methylenetetrahydrofolate reductase (MTHFR) C677T polymorphism, and white matter lesions (WML). The plasma Hcy level and MTHFR C677T gene polymorphism in 104 patients with white matter lesions and 74 controls were measured. The severity of cerebral white matter was scored on the magnetic resonance imaging (MRI) images by the modified Scheltens scale (score of 0-30). The plasma Hcy level in the WML group was remarkably higher than that in the control group $(p<0.05)$, and the proportion of the patients with a high Hcy level in the WML group was notably higher than that in the control group ( $p<0.05)$. Moreover, the patients with TT genotype in MTHFR gene had a significantly higher plasma Hcy level than those with CT or CC genotype. In addition, the plasma Hcy level in the patients with CT genotype was also significantly different from that in the patients with CC genotype $(p<0.05)$. The severity of cerebral white matter lesions among the patients with different genotypes in MTHFR gene was not significantly different $(p>0.05)$. The plasma Hcy level is positively correlated with WML and significantly correlated with C677T gene polymorphism in MTHFR gene. The severity of white matter lesions is not correlated with MTHFR C677T gene polymorphism.
\end{abstract}

Key words: brain white matter disease, gene polymorphism, homocysteine, MTHFR, risk factors.

\section{Introduction}

The white matter lesion (WML) is a common type of cerebral small vessel disease. Cerebral white matter lesions in craniocerebral computed tomography (CT) or magnetic resonance imaging (MRI) are characterized by a patchy or diffusive shadow in the paraventricular and (or) semioval center, showing low density in CT and high T2 and Flair signals in MRI [9]. WML causes cognitive dysfunction, declined capability in memory, computing and execution, dysarthria and gait instability in the elderly population, which not only seriously affects the life quality of the patients, but also brings a heavy burden to the family and society $[5,11]$. Thus, it is necessary to study the risk factors and pathogenesis of WML Currently, the risk factors for WML and the mechanisms are still unclear. Previous studies show that there is a certain correlation between hyperhomocysteinemia and WML $[16,18,26]$.

$\mathrm{N}-5, \quad \mathrm{~N}-10$-methylenetetrahydrofolate reductase (MTHFR) is the rate limiting enzyme in the metabolism of Hcy. Studies have found that MTHFR has a certain correlation with cerebrovascular disease [1,2] 
and has a predictive value in ischemic stroke [25]. However, the relationship between MTHFR gene C677T polymorphism and WML is still unclear. This study detected the plasma homocysteine levels and MTHFR C677T gene polymorphism in the patients with WML and evaluated the severity of WML by the modified Scheltens scale, aiming to explore the risk factors and pathogenesis of WML.

\section{Material and methods Subjects}

The clinical data of 104 patients with WML who were hospitalized in the Department of Neurology of the Second People's Hospital of Lianyungang from March 2015 to June 2016 were collected. The patients included 64 males and 40 females, with an average age of $67.26( \pm 8.32)$ years. Inclusion criteria were as follows: (1) patients aged $45-80$ years; and (2) meeting the diagnostic standard for white matter lesions [22]. Exclusion criteria included: (1) patients with a previous history of stroke; (2) caused by other diseases such as immune, hypoxia, poisoning and genetics; (3) taking folic acid and vitamin B; (4) with Alzheimer's disease, Parkinson's disease, alcoholism and other cognitive function; (5) with a dysfunction or failure in heart, lung, liver, kidney and other important organs; (6) cannot have the head MRI scan. Seventy-four healthy individuals with normal head MRI results, aged 45-80 years, were collected as the control group from the outpatient department of our hospital in the same period. This study was conducted in accordance with the Declaration of Helsinki. This study was conducted with an approval from the Ethics Committee of the Soochow University. Written informed consent was obtained from all participants.

\section{General information}

The age, gender, education (years), smoking and drinking history, histories of hypertension, diabetes, hyperlipidemia, coronary heart disease and plasma Hcy level of each subjects were recorded.

\section{Hcy level detection}

Extracted $2 \mathrm{ml}$ from the median vein of the elbow, placed in EDTA anticoagulant tube and $3000 \mathrm{rpm}$ centrifugation for 10 minutes were taken on an empty stomach. The level of plasma Hcy was detected by using the BeckMan AU5800 automatic biochemical analyzer. The normal range of Hcy was 0 10 $\mu \mathrm{mol} / \mathrm{l}$, and Hcy $>10 \mu \mathrm{mol} / \mathrm{l}$ was defined as hyperhomocysteinemia.

\section{MRI scoring}

A modified Scheltens scale (0-30 scores) was used to score the cranial MRI images of the patients with WML by two experienced radiologists. The basal ganglia and subtentorial lesions and the paraventricular and deep lesions were scored separately using the modified Scheltens scale (score of 0-30) [21]. The paraventricular high signals (0-6 scores) were scored as follows: the hat-shaped high intensity in the occipital lobe and frontal lobe were both scored as 0 -2, and the banded high signals in the lateral ventricle were scored as $0-2$. No lesion, lesions $\leq 5 \mathrm{~mm}$ and lesions with a size of $6-10 \mathrm{~mm}$ were scored as 0,1 and 2, respectively. Hyperintensities of the white matter were scored 0-24 as follows: WML in the frontal, parietal, occipital and temporal lobes was rated $0-6$, respectively. No abnormality was scored 0 ; the lesions smaller than or equal to $3 \mathrm{~mm}$ and the number of less than or equal to 5 were scored 1 ; the lesions smaller than or equal to $3 \mathrm{~mm}$ and the number of more than 6 were scored 2; the lesions within 4-10 mm and the number of less than or equal to 5 were scored 3; the lesion within 4-10 $\mathrm{mm}$ and the number equal to or more than 6 were scored 4; the lesions larger than $11 \mathrm{~mm}$ and the number of more than 1 were scored 5; and the fused lesions were scored 6.

\section{Detection of gene polymorphisms}

Genomic DNA was extracted from $2 \mathrm{ml}$ vein blood which had been placed in the EDTA anticoagulant tube and stored at $-20^{\circ} \mathrm{C}$. Blood genomic DNA Kit (Axygen, USA) was used for DNA extraction according to the instructions provided by the manufacturer.

The primer sequences used for PCR amplification were: (forward) 5'-TGAAGGAGAAGGTGTCTGCGGGA-3', (reverse) 5'-AGGACGGTGCGGTGAGAGTG-3' (Applied Biosystems, USA). The volume of the $P C R$ reaction system was $25 \mu$ l, which contained $1 \mu$ l genome DNA, $2.5 \mu \mathrm{l} 10 \times$ PCR buffer (including $\mathrm{Mg}^{2+}$ ), $2 \mu \mathrm{l} 2.5 \mathrm{mmol} / \mathrm{l}$ dNTP, $1 \mu$ l of both the forward and reverse primers (100 pmol/ $\mu \mathrm{l}), 5 \mathrm{U} / \mu \mathrm{l}$ Taq polymerase $0.125 \mu \mathrm{l}$ and $\mathrm{H}_{2} \mathrm{O} 17.375 \mu \mathrm{l}$. The $\mathrm{PCR}$ reactions were run in the following conditions: pre-denaturation at $94^{\circ} \mathrm{C}$ for $10 \mathrm{~min}, 39$ cycles of denaturation at $94^{\circ} \mathrm{C}$ for $45 \mathrm{~s}$, 
annealing at $62^{\circ} \mathrm{C}$ for $40 \mathrm{~s}$ and extension at $72^{\circ} \mathrm{C}$ for $45 \mathrm{~s}$, and a terminal extension at $72^{\circ} \mathrm{C}$ for $7 \mathrm{~min}$.

The PCR products were analyzed for identification of variants MTHFR C677T using a TaqMan SNP Genotyping Assay (Applied Bio-systems Inc., Foster City, Calif., USA) according to the previous report [28]. All assays were performed in duplicate, and an automatic allele of quality value was used to determine genotype assignment. TaqMan assay was performed to genotype subjects with indeterminate results by direct sequencing of the $P C R$ amplification containing the MTHFR C677T locus.

\section{Statistical analysis}

SPSSv.17 statistical software was used for statistical analysis. The measurement data were expressed as mean \pm standard deviation (SD) and analyzed using $t$ test. Enumeration data were expressed as a percentage (\%) and compared using $\chi^{2}$ test. ANOVA was used to compare the mean of multiple samples. The influencing factors of WML were analyzed by multivariate Logistic regression. The difference was statistically significant when $p<0.05$.

\section{Results}

\section{Clinical data}

MRI score of patients in WML and control group is shown in Figure 1A. There was no statistically significant difference in gender composition, education duration, smoking and drinking history, diabetes

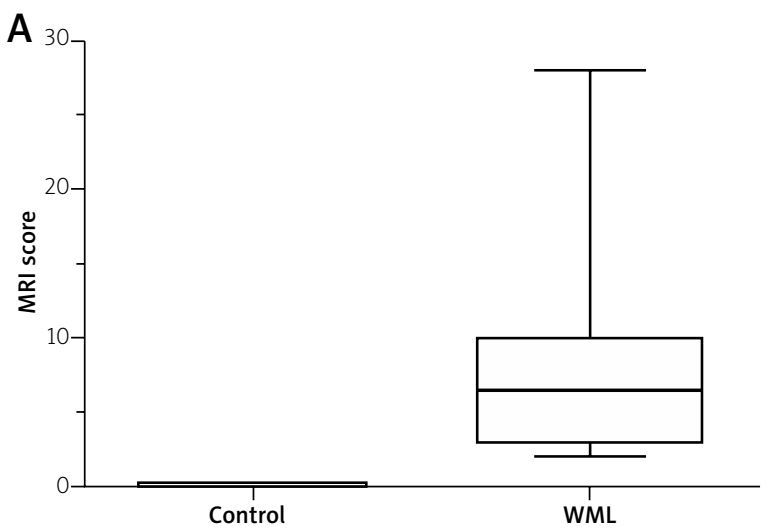

mellitus, coronary heart disease (CHD) and hyperlipidemia between the WML group and the control group ( $p>0.05$ ), while the age, hypertension and Hcy level in the WML group were significantly higher than those in the control group ( $p<0.05)$, indicating that age, hypertension and hyperhomocysteinemia were risk factors for WML (Table I, Fig. 1B).

\section{Genotyping scatter plot of MTHFR}

According to the scatter plot of genotyping, there were 50 cases with CC genotype including 26 cases in the WML group and 24 cases in the control group, 93 cases with CT heterozygous type including 56 cases in the WML group and 37 cases in the control group, and 35 cases with TT homozygous type including 22 cases in the WML group and 13 cases in the control group (Fig. 2).

\section{Gene frequency distribution of MTHFR C677T genotypes}

The gene frequency distribution of MTHFR C677T genotypes showed no statistical difference between the WML group and the control group ( $p>0.05$, Table II).

\section{Comparisons of plasma Hcy levels among the MTHFR C677T genotypes}

According to the carrying of MTHFR C677T genotypes, samples were divided into TT, CT and CC groups, and then the plasma Hcy levels were compared among them. The plasma Hcy level was the highest in

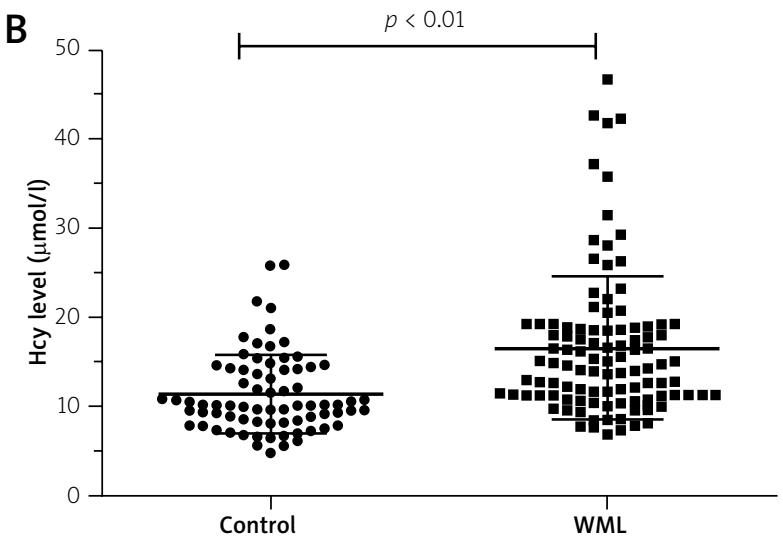

Fig. 1. MRI score and plasma Hcy levels of patients. MRI scores of patients are shown in A). $n=104$ in the white matter lesions (WML) group and $n=74$ in the control group. B) Plasma Hcy levels of WML and control patients were measured. The number of samples in both WML and control groups are consistent with patients with MRI score. 
Table I. Comparison of the general data and the risk factors for stroke between the two groups

\begin{tabular}{|lccc|}
\hline General data & WML group & Control group & $p$ value \\
\hline Age (years)* & $67.26 \pm 8.32$ & $59.45 \pm 7.16$ & 0.001 \\
\hline Gender (male \%) & $61(58.7)$ & $43(58.1)$ & 0.942 \\
\hline Education duration* & $9.7 \pm 3.2$ & $9.2 \pm 2.9$ & 0.472 \\
\hline Smoking (\%) & $47(45.2)$ & $29(39.2)$ & 0.308 \\
\hline Drinking (\%) & $23(22.1)$ & $11(14.9)$ & 0.225 \\
\hline Hypertension (\%) & $75(76.0)$ & $22(29.7)$ & 0.001 \\
\hline Diabetes (\%) & $17(16.3)$ & $9(12.2)$ & 0.412 \\
\hline Hyperlipidemia* & $4.56 \pm 1.13$ & $4.46 \pm 1.07$ & 0.682 \\
\hline CHD (\%) & $8(7.7)$ & $4(5.4)$ & 0.549 \\
\hline Hcy (mmol/l)* & $16.81 \pm 5.18$ & $11.40 \pm 3.72$ & 0.005 \\
\hline
\end{tabular}

*Data are shown as mean $\pm S D$. WML - white matter lesions, CHD - coronary heart disease, Hcy - homocysteine.

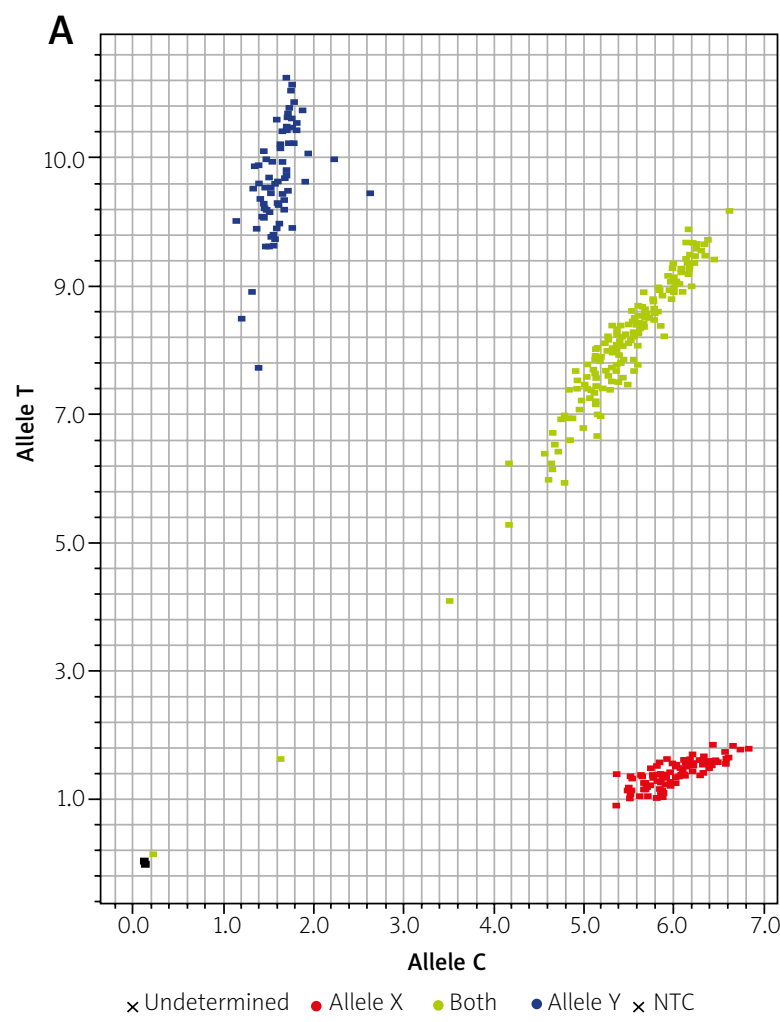

the TT group, followed by the CT group and then the CC group, with statistically significant differences $(p<0.05$, Table III).

\section{Risk factors of WML}

Logistic regression analysis of age, sex, smoking and drinking history, hypertension, diabetes and hyperlipidemia showed that age and hypertension were independent risk factors for WML.

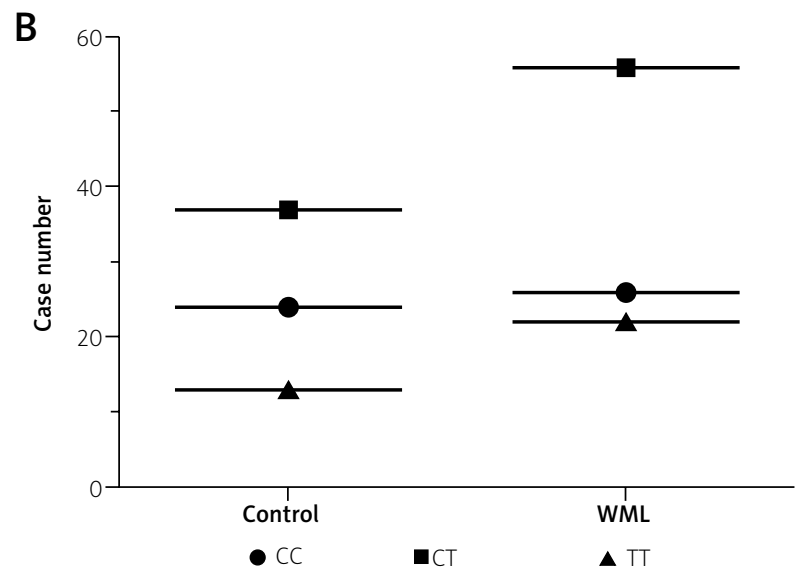

Fig. 2. Genotyping scatter plot of MTHFR. A) Y axis - $T$ alleles; $X$ axis $-C$ alleles; the blue dots near the $Y$ axis belong to TT genotype, the central green dots belong to $\mathrm{CT}$ genotype, and the red dots near the $X$ axis belong to CC genotype. B) Case numbers of CC, CT and TT in the control and white matter lesions (WML) groups.

Taking WML as the dependent variable and the genotypes of MTHFR C677T and Hcy level as the independent variables, the multivariate Logistic regression analysis was carried out. The results showed that a high Hcy level was significantly correlated with the severity of WML lesions (Wald = 6.278, $p=0.021, \mathrm{OR}=2.423,95 \% \mathrm{Cl}=1.136-5.817$ ), and notably associated with MTHFR gene polymorphism. However, there was no significant correlation 
Table II. Comparisons of the gene frequency distribution of MTHFR C677T in the two groups

\begin{tabular}{|lcccccc|}
\hline Groups & Case number & \multicolumn{3}{c}{ Genotypes } & \multirow{2}{*}{$\chi^{2}$ value } & $p$ value \\
\cline { 3 - 6 } & & CC & CT & TT & & \\
\hline WML & 104 & 26 & 56 & 22 & 1.397 & 0.443 \\
\hline Control & 74 & 24 & 37 & 13 & - & - \\
\hline
\end{tabular}

Data were compared with the control group.

$W M L$ - white matter lesions

Table III. Plasma Hcy levels among the three genotypes of MTHFR C677T gene locus

\begin{tabular}{|lcccccc|}
\hline Genotypes & & Case number & Mean $(\mu \mathrm{mol} / \mathrm{l})$ & SD & $F$ value & $p$ value \\
\hline \multirow{2}{*}{$\begin{array}{l}\text { MTHFR } \\
\text { C677T }\end{array}$} & CC & 26 & 13.55 & 0.538 & & \\
\cline { 2 - 7 } & CT & 56 & 16.02 & 0.762 & 1.286 & 0.026 \\
\hline
\end{tabular}

between the polymorphism of MTHFR gene and the severity of WML $(p>0.05)$.

\section{Discussion}

With the coming of the aging society and the popularization of head $\mathrm{MRI}$, the detection rate of WML is getting higher and higher. The etiology of WML may be related to endothelial dysfunction, chronic cerebral hypoperfusion, blood-brain barrier destruction, and auto-regulatory dysfunction of small vessels $[10,15]$.

The present study suggested that hyperhomocysteinemia is associated with WML, and is one of the risk factors for WML $[3,17,24]$. Vermeer et al. [24] found that the WML risk in the patients with the plasma Hcy level in the highest 5 percentile was 2.3 times higher than that in the lowest 5 percentile after correcting other risk factors, indicating that Hcy is an independent risk factor for WML. Pavlovic et al. [17] have found that a high plasma Hcy level are positively correlated with the severity of brain white matter disease, which can be used as an independent predictor for WML. Kloppenborg et al. [13] applied MRI to measure the volume of WML and found that hyperhomocysteinemia is positively correlated with the volume of WML, and has a significant correlation with the risk of its progression $(\mathrm{OR}=2.4, p<0.001)$. Feng et al. [7] studied the relationship between hyperhomocysteinemia and cerebral macroangiopathy and small vessel disease and found that hyperhomocysteinemia is closely related to cerebral small vessel disease and it is an independent risk factor for cerebral small vessel disease $(\mathrm{OR}=1.315, p<0.001)$. The results in this study showed that the Hcy level in the WML group was significantly higher than that in the control group, indicating that hyperhomocysteinemia is an independent risk factor for WML, which is consistent with the domestic and foreign research results. The possible mechanism is that Hcy causes endothelial function injury in small blood vessels of brain via the pathways such as oxidative stress and influencing the vasomotor function.

Hcy level is mainly affected by the activity of its rate-limiting enzyme $\mathrm{N}-5, \mathrm{~N}-10$-methylenetetrahydrofolate reductase (MTHFR). The main reason for the increase in the Hcy level is attributed to the polymorphism of MTHFR gene. C677T polymorphism is the most common polymorphism in MTHFR gene, in which $C$ base is substituted by $T$ base, leading to the encoding alanine substituted by valine. The substitution of alanine by valine results in the decrease in MTHFR activity and leads to the elevated level of Hcy. Studies have found that the enzyme activity of MTHFR with homozygous TT genotype is only $30 \%$ of the normal, and that with heterozygous CT genotype is only $65 \%$ of the normal, resulting in the plasma Hcy level in the patients with homozygous TT genotype increases significantly as compared with that in the patients with heterozygous CT genotype or wild-type (CC). The frequency of $\mathrm{T}$ alleles is different to a great extent in different countries and nationalities. It is significantly higher in the Chinese population than in the European and American population $[27,29]$. Whether the gene polymorphism of MTHFR C677T is associated with WML remains controversial. Rajagopalan et al. [19] followed up 359 patients with mild cognitive impairment for twelve months and found that T allele in MTHFR gene is significantly related to the volume of white matter. De Lau et al. [23] found that the MTHFR C677T gene 
polymorphism is only related to Hcy level, but has no significant correlation with the brain white matter lesions. A study of Jeon et al. [12] has shown that a high Hcy level is associated with cerebral small vessel disease, and TT genotype of MTHFR is an important determinant of hyperhomocysteinemia, but MTHFR gene polymorphism is not correlated with cerebral small vessel disease. Rutten-Jacobs et al. [20] found that MTHFR C677T polymorphism is closely related to the volume of white matter lesions, which influences the white matter lesions by increasing their sensitivity to hypertension or increasing their interaction with hypertension. In this study, we found that the polymorphism of MTHFR C677T gene was significantly correlated with the Hcy level, but had no remarkable relationship with the severity of white matter lesions, which was consistent with the research results of Tran et al. [23]. Our results were only from a cross-sectional survey, thus further epidemiological and prospective studies are needed to demonstrate our findings.

It was reported that MTHFR C677T polymorphisms is a risk factor for autism [8], biological role of MTHFR gene polymorphism in pregnancy [30] and association between allergic rhinitis and polymorphisms of C677T for MTHFR gene in children [6] needed further study. MTHFR polymorphisms (C667T) may be not associated with pancreatic cancer risk indicated by meta-analysis [14]. In conclusion, the roles of MTHFR polymorphisms in many diseases need further study.

At present, the diagnosis of WML mainly depends on MRI. There are still many problems in the studies on WML. Early identification of WML using imaging, Hcy, MTHFR and other relevant indicators and early intervention for the risk factors of WML can help to predict the incidence risk of WML and prevent or delay the occurrence of WML, so as to reduce the severity of WML, improve the quality of life of the patients and reduce the burden of family and society.

\section{Acknowledgements}

This work was supported by the Projects from the Science and Technology Bureau of Lianyungang (SH1538) and the Project from Key Disciplines of Lianyungang (SH1602).

\section{Conflicts of interest}

The authors report no conflict of interest.

\section{References}

1. Abhinand PA, Manikandan M, Mahalakshmi R, Ragunath PK. Meta-analysis study to evaluate the association of MTHFR C677T polymorphism with risk of ischemic stroke. Bioinformation 2017; 13: 214-219.

2. Chang YT, Hsu SW, Tsai SJ, Chang YT, Huang CW, Liu ME, Chen NC, Chang WN, Hsu JL, Lee CC, Chang CC. Genetic effect of MTHFR C677T polymorphism on the structural covariance network and white-matter integrity in Alzheimer's disease. Hum Brain Mapp 2017; 38: 3039-3051.

3. Cloonan L, Fitzpatrick KM, Kanakis AS, Furie KL, Rosand J, Rost NS. Metabolic determinants of white matter hyperintensity burden in patients with ischemic stroke. Atherosclerosis 2015; 240: 149-153.

4. de Lau LM, van Meurs JB, Uitterlinden AG, Smith AD, Refsum H, Johnston C, Breteler MM. Genetic variation in homocysteine metabolism, cognition, and white matter lesions. Neurobiol Aging 2010; 31: 2020-2022.

5. Della-Morte D, Dong C, Markert MS, Elkind MSV, Sacco RL, Wright CB, Rundek T. Carotid Intima-Media Thickness Is Associated With White Matter Hyperintensities: The Northern Manhattan Study. Stroke 2018; 49: 304-311.

6. Dogru M, Aydin H, Aktas A, Cirik AA. Methylenetetrahydrofolate Reductase gene polymorphism in children with allergic rhinitis. Allergol Immunopathol (Madr) 2015; 43: 579-583.

7. Feng C, Bai X, Xu Y, Hua T, Huang J, Liu XY. Hyperhomocysteinemia associates with small vessel disease more closely than large vessel disease. Int J Med Sci 2013; 10: 408-412.

8. Guo T, Chen H, Liu B, Ji W, Yang C. Methylenetetrahydrofolate reductase polymorphisms $C 677 \mathrm{~T}$ and risk of autism in the Chinese Han population. Genet Test Mol Biomarkers 2012; 16: 968-973.

9. Hachinski VC, Potter P, Merskey H. Leuko-araiosis. Arch Neurol 1987; 44: 21-23.

10. Hainsworth AH, Fisher MJ. A dysfunctional blood-brain barrier and cerebral small vessel disease. Neurology 2017; 88: 420-421.

11. Hofer E, Cavalieri M, Bis JC, DeCarli C, Fornage M, Sigurdsson S, Srikanth V, Trompet S, Verhaaren BF, Wolf C, Yang Q, Adams HH, Amouyel P, Beiser A, Buckley BM, Callisaya M, Chauhan G, de Craen AJ, Dufouil C, van Duijn CM, Ford I, Freudenberger P, Gottesman RF, Gudnason V, Heiss G, Hofman A, Lumley T, Martinez O, Mazoyer B, Moran C, Niessen WJ, Phan T, Psaty BM, Satizabal CL, Sattar N, Schilling S, Shibata DK, Slagboom PE, Smith A, Stott DJ, Taylor KD, Thomson R, Töglhofer AM, Tzourio C, van Buchem M, Wang J, Westendorp RG, Windham BG, Vernooij MW, Zijdenbos A, Beare R, Debette S, Ikram MA, Jukema JW, Launer LJ, Longstreth WT Jr, Mosley TH, Seshadri S, Schmidt $\mathrm{H}$, Schmidt R; Cohorts for Heart and Aging Research in Genomic Epidemiology Consortium. White Matter Lesion Progression: Genome-Wide Search for Genetic Influences. Stroke 2015; 46: 3048-3057.

12. Jeon SB, Kang DW, Kim JS, Kwon SU. Homocysteine, small-vessel disease, and atherosclerosis: an MRI study of 825 stroke patients. Neurology 2014; 83: 695-701.

13. Kloppenborg RP, Geerlings MI, Visseren FL, Mali WP, Vermeulen $M$, van der Graaf Y, Nederkoorn PJ; SMART Study Group. Homo- 
cysteine and progression of generalized small-vessel disease: the SMART-MR Study. Neurology 2014; 82: 777-783.

14. Li L, Wu SD, Wang JY, Shen XZ, Jiang W. MTHFR polymorphisms and pancreatic cancer risk: lack of evidence from a meta-analysis. Asian Pac J Cancer Prev 2012; 13: 2249-2252.

15. Nezu T, Hosomi N, Aoki S, Kubo S, Araki M, Mukai T, Takahashi T, Maruyama H, Higashi Y, Matsumoto M. Endothelial dysfunction is associated with the severity of cerebral small vessel disease. Hypertens Res 2015; 38: 291-297.

16. Pařizková M, Andel R, Lerch O, Marková H, Gažová I, Vyhnálek M, Hort J, Laczó J. Homocysteine and Real-Space Navigation Performance among Non-Demented Older Adults. J Alzheimers Dis 2017; 55: 951-964.

17. Pavlovic AM, Pekmezovic T, Obrenovic R, Novakovic I, Tomic G, Mijajlovic M, Sternic N. Increased total homocysteine level is associated with clinical status and severity of white matter changes in symptomatic patients with subcortical small vessel disease. Clin Neurol Neurosurg 2011; 113: 711-715.

18. Poggesi A, Pasi M, Pescini F, Pantoni L, Inzitari D. Circulating biologic markers of endothelial dysfunction in cerebral small ves sel disease: A review. J Cereb Blood Flow Metab 2016; 36: 72-94.

19. Rajagopalan P, Jahanshad N, Stein JL, Hua X, Madsen SK, Kohannim O, Hibar DP, Toga AW, Jack CR Jr, Saykin AJ, Green RC, Weiner MW, Bis JC, Kuller LH, Riverol M, Becker JT, Lopez OL, Thompson PM; Alzheimer's Disease Neuroimaging Initiative (ADNI); Cardiovascular Health Study (CHS). Common folate gene variant, MTHFR C677T, is associated with brain structure in two independent cohorts of people with mild cognitive impairment. Neuroimage Clin 2012; 1: 179-187.

20. Rutten-Jacobs LC, Traylor M, Adib-Samii P, Thijs V, Sudlow C, Rothwell PM, Boncoraglio G, Dichgans M, Meschia J, Maguire J, Levi C, Rost NS, Rosand J, Hassan A, Bevan S, Markus HS. Association of MTHFR C677T Genotype With Ischemic Stroke Is Confined to Cerebral Small Vessel Disease Subtype. Stroke 2016; 47: 646-651.

21. Scheltens P, Barkhof F, Leys D, Pruvo JP, Nauta JJ, Vermersch P, Steinling $M$, Valk J. A semiquantative rating scale for the assessment of signal hyperintensities on magnetic resonance imaging. I Neurol Sci 1993; 114: 7-12.

22. Smith EE. Leukoaraiosis and stroke. Stroke 2010; 41: S139-143.

23. Tran T, Cotlarciuc I, Yadav S, Hasan N, Bentley P, Levi C, Worrall BB, Meschia JF, Rost N, Sharma P. Candidate-gene analysis of white matter hyperintensities on neuroimaging. I Neurol Neurosurg Psychiatry 2016; 87: 260-266.

24. Vermeer SE, van Dijk EJ, Koudstaal PJ, Oudkerk M, Hofman A, Clarke R, Breteler MM. Homocysteine, silent brain infarcts, and white matter lesions: The Rotterdam Scan Study. Ann Neurol 2002; 51: 285-289.

25. Vijayan M, Chinniah R, Ravi PM, Sivanadham R, Mosses Joseph AK, Vellaiappan NA, Krishnan JI, Karuppiah B. MTHFR (C677T) CT genotype and $\mathrm{CT}$-apoE3/3 genotypic combination predisposes the risk of ischemic stroke. Gene 2016; 591: 465-470.

26. Wang CY, Chen ZW, Zhang T, Liu J, Chen SH, Liu SY, Han LY, Hui ZH, Chen YM. Elevated plasma homocysteine level is associated with ischemic stroke in Chinese hypertension patients. Eur J Intern Med 2014; 25: 538-544.

27. Yang B, Fan S, Zhi X, Xia R, Wang Y, Zheng Q, Sun G. Geographical and ethnic distribution of MTHFR gene polymorphisms and their associations with diseases among Chinese population. Clin Genet 2017; 92: 243-258.

28. Yan H, Wu A. FOXO1 is crucial in glioblastoma cell tumorigenesis and regulates the expression of SIRT1 to suppress senescence in the brain. Mol Med Rep 2018; 17: 2535-2542.

29. Zhang L, Yin RX, Liu WY, Miao L, Wu DF, Aung LH, Hu XJ, Cao XL, Wu JZ, Pan SL. Association of methylenetetrahydrofolate reductase C677T polymorphism and serum lipid levels in the Guangxi Bai Ku Yao and Han populations. Lipids Health Dis 2010; 9: 123.

30. Zhu Y, Wu T, Ye L, Li G, Zeng Y, Zhang Y. Prevalent genotypes of methylenetetrahydrofolate reductase (MTHFR) in recurrent miscarriage and recurrent implantation failure. J Assist Reprod Genet 2018; 35: 1437-1442. 